\title{
Rare Incidental Detection of Bombay Blood Group in A Patient of Marfans Syndrome with Subsequent Clustering and Unusual Inheritance Pattern in Four Individuals of Same Family in South West Region of Punjab
}

\author{
Anshul Gupta ${ }^{1}$, Sahil Chhabra ${ }^{1 *}$, Jagsir Singh ${ }^{2}$, Harshi Dhingra ${ }^{1}$, Anamika ${ }^{1}$, Bhaskar Jain ${ }^{1}$ \\ 'Department of Pathology, Adesh Institute of Medical Sciences and Research, Bathinda, India \\ ${ }^{2}$ Department of Orthopaedics, Adesh Institute of Medical Sciences and Research, Bathinda, India
}

\begin{abstract}
The Bombay Blood Group (Oh) is characterized by absence of normal ABH antigens and presence of corresponding antibodies in serum. This blood group is suspected when a sample doesn't show any reaction to anti-A and anti-B antibodies just like a normal O group would do but shows agglutination in reverse grouping or during antibody screening. Present case report highlights a case of 25 year old female who was incidentally detected having Bombay blood group and on further evaluation one sibling and two first degree cousins were also detected having Bombay blood group. Such a clustering of Bombay blood group cases in a single family is very rare and has never been reported in Punjab as per literature.
\end{abstract}

Keywords: Rare Blood Group, Bombay Blood Group

\section{Introduction}

In December 1951, trauma patient admitted to K.E.M. hospital was found to be O-Positive but on cross-matching his serum agglutinated all $\mathrm{O}$ group cells. So only plasma was transfused. Further research work was carried out and in 1952 Dr. Y.M. Bhende discovered the Bombay blood group. ${ }^{1}$

Bombay phenotype is as a result of point mutation in FUT1 gene which is located on chromosome no 19. ${ }^{2}$ The Bombay Blood Group is characterised by absence of normal ABH antigens and have co-responding antibodies in serum. This blood group is suspected when a sample doesn't show any reaction to anti-A and anti-B antibodies just like a normal $\mathrm{O}$ group would do but shows agglutination in reverse or back typing or during antibody screening. ${ }^{3}$

H-deficient Bombay phenotype is rare, since it occurs in about 1 in 10,000 individuals in India and 1 per 1,000,000 individuals in Europe. ${ }^{4}$

The difficulty with the Bombay phenotype is that the individuals having blood group of Bombay phenotype (Oh) can either receive autologous donation or blood from an individual of Bombay phenotype only; no other blood will match in case of an emergency blood transfusion.

\section{Case Report}

A 25 year old female presented to orthopaedics outpatient with history of fall post which she had difficulty in walking. Radiological investigations revealed a fracture neck of femur. On further clinical examination she was found to have Marfanoid features(habitus) including a high arched palate, lower segment $>$ upper segment of body. She was further advised ophthalmologic examination and 2D ECHO. Fundoscopy revealed bilateral anterosuperior subluxation of lens and echocardiography showed that she had mild mitral regurgitation. She was planned to undergo operate for fracture neck of femur but she had haemoglobin of $7 \mathrm{gm} / \mathrm{dl}$, so family was asked to arrange for blood. On carrying out forward, reverse grouping and running control with $\mathrm{O}$ positive red cells, it was found that she had anti A, anti B antibodies. Also her serum reacted against the control $\mathrm{O}$ blood group red cells. Further crossmatching was done with $\mathrm{O}$ blood group red cells but it showed incompatibility. Thus, she had anti A, anti B and anti $\mathrm{H}$ antibodies in her blood. So, she was diagnosed as Bombay blood group. Because of non availability of suitable donor she was managed by normovolemic hemodilution followed by autologous blood transfusion by collecting her blood 3 weeks prior to surgery.

Further, the family members of patient were counselled to get their blood group done on which it was found that three other family members i.e. brother and two first degree cousin brothers were also found to have Bombay blood group. The pedigree of family was formulated. This was quite unusual finding of clustering of Bombay blood group 
in a family (Fig.1) which has been reported very rarely in few case reports. Further unusual was for a autosomal recessive inheritance trait as Bombay blood group is, to be present in first degree cousins too but due to lack of genetic studies further studies in this aspect couldn't be carried out.

\section{Discussion}

Three separate loci (ABO, Hh, and Se) contain the genes that control the location and occurrence of $\mathrm{A}$ and $\mathrm{B}$ antigens. $\mathrm{Hh}$ and Se genes are linked on chromosome 19. Precursor substance is converted to $\mathrm{H}$ substance with the help on enzyme fucosyl transferase by the action of $\mathrm{H}$ gene. ${ }^{5,6} \mathrm{H}$ gene has two alleles, active form $\mathrm{H}$ and amorph form $\mathrm{h}$. Since $\mathrm{h}$ is amorphic gene the heterozygous Hh cannot be recognised. out of which " $\mathrm{H}$ " is a high incidence gene and hh is extremely rare. $\mathrm{H}$ substance is converted by specific transferases namely $\mathrm{N}$ acetyl galactosaminyl transferase and $\mathrm{D}$ galactosyl tranferase to $\mathrm{A}$ and $\mathrm{B}$ antigens by the attachment of N-Acetyl-Galactosamine and D-Galactose respectively to $\mathrm{H}$ substance. ${ }^{7}$ The blood group resulting from homozygous "hh" condition is called the Bombay (Oh) Blood group. ${ }^{7}$

The Bombay blood group is more common in western and southern parts of india as compared to northern and rest of Indian states. ${ }^{6}$ Incidence is higher in those states of india where cosanguinous marriages are more prevelant. The clustering of Bombay blood group cases in four individuals of same family is very rare and only very few case reports mention this occurrence in a family. Aust $\mathrm{CH}$ et al reported this occurrence in their paper published in 1962 in four individuals of same family. ${ }^{8}$ A recent study in 2015 titled "Bombay Blood Group in a Turkish Family: Serological and Molecular Analysis" also describes similar clustering of Bombay blood group in a family. ${ }^{9}$

Further in our case report it was also found that inheritance pattern was unusual for a autosomal recessive trait to express itself in first degree cousins. However, due to lack of resources, further studies couldn't be carried out and are warranted to see the inheritance pattern.

Although the proband in our case also had Marfan's syndrome no correlation between occurrence of this syndrome and Bombay blood group was found in literature.

\section{Conclusion}

Since Bombay blood group is a rare blood group the individuals having this blood group can receive blood only from an individual having similar blood group, so whenever a case of this rare blood group is discovered a pedigree analysis is always helpful to find someone in family with similar blood group as it has been seen in literature and also in this study that family members and first degree relatives had Bombay blood group.

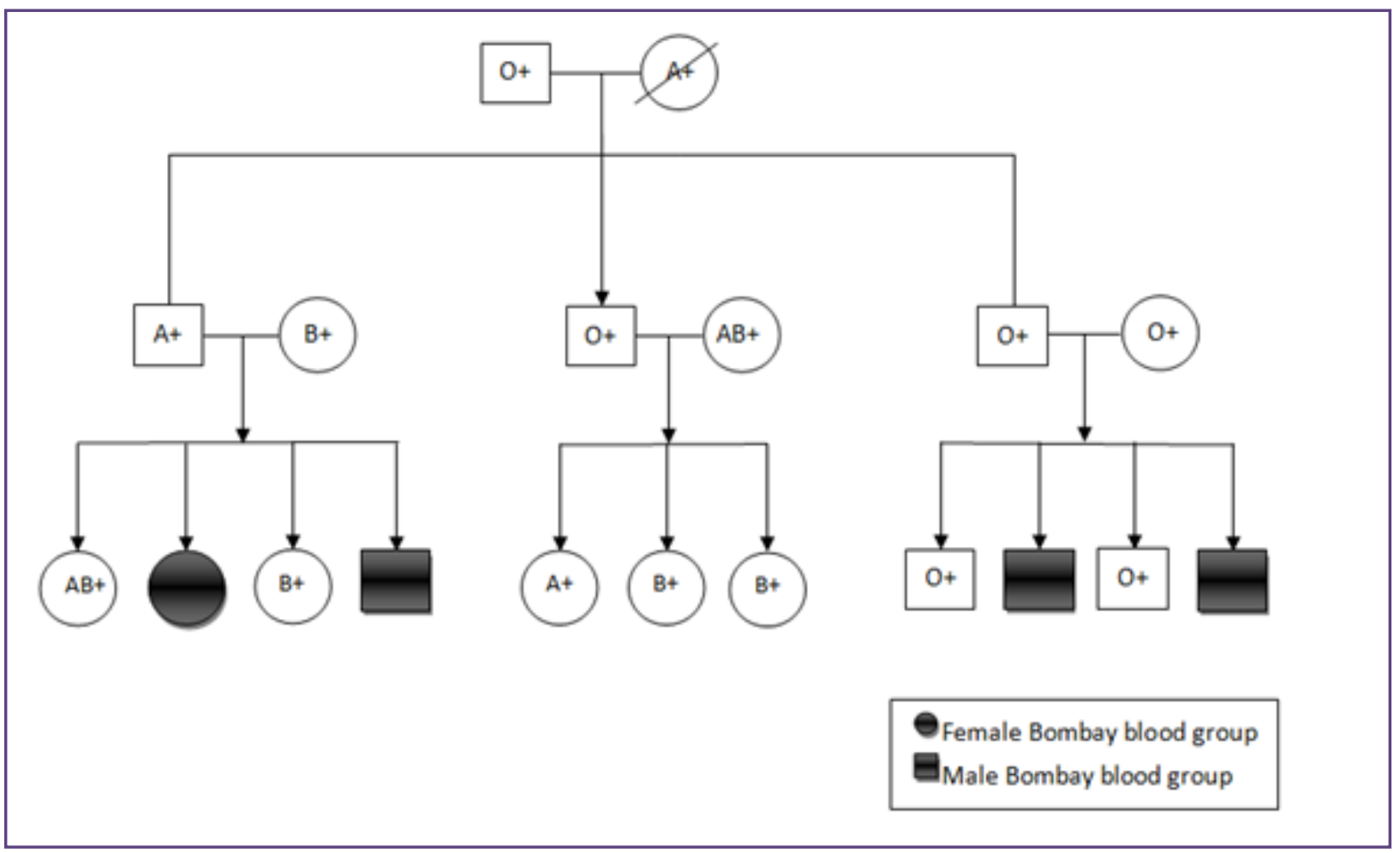

Fig. 1: Pedigree chart of family. 


\section{References}

1. Bhende Y M, Deshpande C K, Bhatia H M, Sanger R, Race $\mathrm{R} R$, Morgan W T. A new blood group character related to the ABO system Lancet. 1952 May 3;1(6714):903-4.

2. Das S, Kumar HRA. Bombay Blood A Rare Entity. Journal of Clinical Biomedical Science. 2011;1(3):122-5.

3. Khan M. Bombay Blood Group: A Case Report. The Pacific Journal of Science and Technology. 2009 May;10(1):333-7.

4. Bombay Blood Group in a Turkish Family: Serological and Molecular Analysis. Aytac R et al. Indian Journal of Hematology and Blood Transfusion. 2015;31(3):396-7.

5. Kelly RJ, Rouquier S, Giorgi D, Lennon GG, Lowe JB. Sequence and expression of a candidate for the human secretor blood group a-(1,2)-fucosyltransferase gene (FUT2). Homozygosity for an enzyme-inactivating nonsense mutation commonly correlates withthe nonsecretor phenotype. J Biol Chem. 1995;270:4640-9.
6. Larsen RD, Ernst LK, Nair RP, Lowe JB. Molecular cloning, sequence, and expression of a human GDP-L-fucose: b-Dgalactoside 2-a-L-fucosyltransferase cDNA that can form the H blood group antigen. Proc Natl Acad Sci USA. 1990; 87:6674-8.

7. Saran RK. Transfusion Medicine: Technical Manual. Directorate General of Health Services, Ministry of Health and Family Welfare, Government of India; 2003.

8. Aust $\mathrm{CH}$ et al. A family of Bombay blood type with suppression of blood group substance A1. The American Journal Of Clinical Pathology. 1962; 37(6):579-83.

9. Rıza Aytaç Çetinkaya, Soner Yılmaz, Davut Gül, Sebahattin Yılmaz, İsmail Yaşar Avcı,, Can Polat Eyigün Bombay Blood Group in a Turkish Family: Serological and Molecular Analysis. Indian Journal of Hematology and Blood Transfusion. 2015; 31(3): 396-7.

*Corresponding author:

Dr. Sahil Chhabra, Department of Pathology, Adesh Institute of Medical Sciences and Research, Bathinda, INDIA

Phone: +9108699017530

Email: drsahil137@gmail.com

Financial or other Competing Interests: None. 